\title{
LA FILOSOFÍA DEL CONCEPTO DE GADAMER
}

\author{
Cirilo Flórez Miguel \\ Universidad de Salamanca
}

\begin{abstract}
RESUMEN. El artículo diferencia en su comienzo las hermenéuticas de Dilthey y de Gadamer. Analiza a continuación el concepto hermenéutico de aplicación, pasando después al análisis de la teoría gadameriana del lenguaje. Diferencia la teoría hegeliana del lenguaje de la de Gadamer, para pasar luego al estudio del concepto en Hegel y Gadamer. Destaca la importancia del texto en la hermenéutica y concluye con la diferenciación de tres filosofías del concepto: Hegel, Gadamer y Koselleck.
\end{abstract}

«La formulación del tema (historia del concepto como filosofía) lleva implícito en todo caso un aserto sobre lo que es la filosofía: que su conceptualidad constituye su esencia, a diferencia de la función de los conceptos en los esquemas de las ciencias positivass!

La pretensión originaria de Gadamer en el punto de partida de su filosofía "era la de la universalidad de la experiencia hermenéutica, que debe ser accesible desde cualquier punto de vista si ha de ser una experiencia universal ${ }^{2}$. El camino elegido por Gadamer para lograr esta pretensión fue la discusión diltheyana del planteamiento de la «comprensión del otro» dentro de las ciencias del espíritu ${ }^{3}$.

Frente al planteamiento diltheyano de la comprensión del otro Gadamer va a proponer como alternativa una teoría general de la comunicación mediada por el lenguaje; interpretando la comunicación ya como diálogo (comunicación en

1 H.-G. GaDAMER, Verdad y Método, II, trad. M. Olasagasti, Sígueme, Salamanca, 1994, 81.

2 Ibídem, 11.

${ }^{3}$ Ibídem, 17. 
presencia) o ya como lectura (comunicación en ausencia). Tanto en un caso como en el otro la comunicación se cumple por mediación de la lingüisticidad del lenguaje. En este proceso hermenéutico mediado por el lenguaje la comunicación adquiere primacía sobre el cultivo del hablar y argumentar que era propio de la retórica. El intérprete entra en comunicación con la tradición y por eso la conciencia lectora del intérprete es constitutivamente histórica. El acto de lectura del intérprete es un acto de participación en lo que el texto dice. No se trata propiamente de una relación entre personas, sino de una participación en un proceso de comunicación sustentado en el fenómeno de la lingüisticidad. «Con ello se hace claro al mismo tiempo que 'repetir' no puede tomarse aquí en sentido estricto; no se refiere a la reconducción de algo a un primum originario en el que algo fue dicho o escrito. La lectura comprensiva no es repetición de algo pasado, sino participación en un sentido presente" ${ }^{4}$. En este proceso lingüístico de la comunicación la categoría de la aplicación pasa a ser una de las categorías fundamentales de la hermenéutica junto a las de explicación y comprensión puestas en juego por la hermenéutica como metodología. El lector del texto aplica el mundo del texto en el presente de su lectura y de ello resulta una experiencia viva que transforma al lector.

\section{La aplicación en la hermenéutica de Gadamer}

Las polémicas modernas de los métodos habían reducido los problemas epistemológicos a la doble línea del comprender y del explicar y habían expulsado del contexto epistemológico el tema hermenéutico de la aplicación, que en las tradiciones filológica, jurídica y teológica había formado parte integrante de la tarea del entender, que según dichas tradiciones estaba integrada por tres tipos de subtilitas: la intelligendi, la explicandi y la applicandi. La comprensión de cualquier texto, ya fuera ley o mensaje, no podía reducirse a su comprensión y explicación, sino que desembocaba necesariamente en una aplicación, ya fuera ésta técnica o práctica.

La aplicación se puede entender como aplicación técnica tal como hizo la ciencia moderna con su teoría del método; o se puede entender como aplicación moral tal como va a hacer Gadamer. En la aplicación moral juega un papel fun-

${ }^{4}$ H.-G. GADAmER, Verdad y Método I, trad. A. Agud, Sígueme, Salamanca, 1977, 471. 
damental la deliberación tanto sobre los fines como sobre los medios. Por eso la aplicación moral implica siempre un saber circunstanciado en el que es importante la experiencia, tal como reconoce Gadamer ${ }^{5}$.

Lo propio del saber moral es que en él el acto de comprensión se desplaza desde el sí mismo a la situación en la que tiene que actuar el otro. Es decir, se da un desplazamiento desde la mismidad a la alteridad. $Y$ la verdadera comprensión del otro sólo se da plenamente cuando el que comprende desea lo justo y se encuentra con el otro en una relación de comunidad, como queda bien ejemplificado en el "consejo del amigo». Este planteamiento de la comprensión es trasladado por Gadamer a la comprensión de textos ${ }^{6}$.

Esta traslación la puede hacer Gadamer porque para él, lo mismo que para Humboldt, el lenguaje lleva consigo una concepción del mundo. "Es sabido que Humboldt enseña a comprender cada lengua como una determinada concepción del mundo, y que lo hacía investigando la forma interior en la que se diferencia en cada caso el acontecer humano originario que es la formación del lenguaje» ${ }^{7}$.

Y no sólo lleva consigo una concepción del mundo, sino "formas y estructuras" que adquieren consistencia más allá de nuestra efímera existencia, y que tienen garantizada la resurrección que les procura el lector que ha sido afectado por ellas. La efímera rosa vive en su nombre. El nombre es el lugar en el que se conservan las efímeras cosas. Para la hermenéutica de Gadamer la palabra no es la expresión del espíritu, sino la simbolización de la cosa misma y por eso es interpretación objetiva de la realidad. «La palabra no expresa al espíritu sino a la cosa a la que se refiere. El punto de partida de la formación de la palabra es el contenido objetivo mismo (la species) que llena al espíritu" ${ }^{8}$.

Aquí reside una de las peculiaridades de la hermenéutica de Gadamer frente a la retórica. La retórica busca el consenso entre los interlocutores sobre algo

${ }^{5}$ Ibidem, 394.

${ }^{6}$ Ibídem, 396.

7 Ibídem, 527-528; 535.

${ }^{8}$ Ibídem, 511. En este punto Gadamer sigue la tradición clásica del simbolismo, que entiende el símbolo como plenitud de la realidad. Esa tradición clásica es opuesta a la tradición moderna o romántica, para la que el signo tiene primacía sobre el símbolo. 
del mundo por medio del lenguaje, pero atiende sobre todo al aspecto oral del mismo y a los efectos del lenguaje sobre los oyentes (dimensión perlocucionaria del lenguaje); mientras que la comprensión hermenéutica de textos es una conversación entre la tradición escrita y el lector intérprete a través de la mediación de la lingüisticidad del texto. El lenguaje del texto es el medio en el que se realiza la conversación hermenéutica; y en esta conversación lo importante es la fuerza ilocucionaria del lenguaje y su poder de decir en cada momento del presente gracias a la conexión del lenguaje escrito con todo el sentido de la tradición. La esencia de lo que Gadamer denomina "literatura" no está en la argumentación como en el caso de la retórica, sino en el poder decir del lenguaje, en la expresión. Dentro del conjunto de las artes la primacía está en las artes que Gadamer engloba en lo que él denomina "literatura», que está integrado por las artes de la escritura. En la literatura como obra de arte escrita se cumple plenamente la concepción que él tiene de la obra de arte como ser. «En consecuencia la forma de arte que es la literatura sólo puede concebirse adecuadamente desde la ontología de la obra de arte, no desde las vivencias estéticas que van apareciendo a lo largo de la lecturan". La ontología de la obra de arte es la que hace que pasen a primer plano la escritura y la lectura frente a la declamación del rapsoda o la argumentación del retórico. «El que la esencia de la tradición se caracterice por su lingüisticidad adquiere su pleno significado hermenéutico allí donde la tradición se hace escrita. En la escritura se engendra la liberación del lenguaje respecto a su realización. Bajo la forma de la escritura todo lo transmitido se da simultáneamente para cualquier presente» ${ }^{10}$.

La comprensión de la literatura desde el punto de vista del lenguaje como expresión supone una peculiar concepción del lenguaje por parte de la hermenéutica de Gadamer. Esta concibe al lenguaje como el lenguaje de la razón y pone el acento en la conceptualidad de la comprensión, insistiendo en la unidad interna del pensamiento y el lenguaje y apartándose de la interpretación psicológica de la comprensión tal como fuera planteada por Dilthey. En este punto la hermenéutica de Gadamer se aparta de Dilthey y se aproxima a Hegel. La idea gadameriana de la unidad interna de pensamiento y lenguaje pone de relieve una teoría actualista del lenguaje similar a la de Austin. La interpretación gadameriana del lenguaje acentúa el poder conceptualizador del mismo. Lo importante del

9 Ibídem, 213.

${ }^{10}$ Ibídem, 468. 
lenguaje es su fuerza; lo que quiere decir que Gadamer da primacía a la consideración poética del lenguaje frente a su consideración lógica (caso de Hegel) o frente a la consideración retórica. Para él el lenguaje es un hacer, como ya defendieran los estoicos frente a la teoría platónica de la copia, así como frente a la teoría aristotélica de la categorización o modos de decir del ser. La teoría estoica del "lektón" y de los incorporales destaca el aspecto acontecimental y activo del lenguaje. "La lógica estoica habla por primera vez de esos significados incorpóreos por medio de los cuales se realiza el hablar sobre las cosas (tò lektón). Y es muy significativo que estos significados se coloquen en el mismo nivel que el tópos, el espacio. Igual que el espacio vacío se convierte en un dato del pensar sólo ahora, cuando se retiran del pensamiento las cosas ordenadas en él, también ahora por primera vez los 'significados' se piensan por sí mismos como tales, y se acuña para ellos un concepto, apartando del pensamiento las cosas designadas a través del significado de las palabras. Los significados son también como un espacio en el que las cosas se ordenan unas con otras" ${ }^{11}$.

La teoría gadameriana del lenguaje es una teoría actualista, que él precisa recurriendo a la teoría de Humboldt, para quien las distintas lenguas son productos de la fuerza del espíritu humano. Y además cada una de ellas expresa una determinada concepción del mundo. Cosa que no se logra solamente por la forma interior que la caracteriza, tal como dice Humboldt, sino también por el contenido (concepto) que la misma transmite. "La forma lingüística y el contenido transmitido no pueden separarse de la experiencia hermenéutica. Si cada lengua es una concepción del mundo, no lo es tanto en su calidad de representante de un determinado tipo de lengua (que es como considera la lengua el lingüista), sino en virtud de aquello que se ha hablado y transmitido en ella" ${ }^{12}$.

Forma y contenido quedan articulados en la fuerza que es el lenguaje; aspecto este que se hace claramente manifiesto en la estructura reflexiva del verbo, que hace visible todo y se hace visible a sí mismo en el expresarse, del mismo modo que la luz hace visible todo lo demás y también a sí misma. En el fondo de esta teoría lingüística de Gadamer se asienta una teoría de la expresión, entendiendo este término desde el punto de vista de la tradición latina de "expressio" y "expri-

1 Ibídem, 519.

12 Ibídem, 529. 
meren, y no desde el punto de vista de la psicología vivencial. De acuerdo con la tradición latina, "expresión» no significa que uno se expresa a sí mismo en el lenguaje, sino que el lenguaje expresa algo gracias al poder de que está dotado. «El lenguaje como producto de la reflexión creadora, que da su ser al poema, es expresión de un todo vivo pero particular» ${ }^{13}$. Esta interpretación de "expression y de «exprimere» está íntimamente ligada a la tradición neoplatónica y a través de ella va a desembocar en la filosofía de Spinoza, que reconoce en la expresión un concepto ontológico fundamental ${ }^{14}$; y va a llegar a $\mathrm{Hegel}$, que "ve la verdadera realidad del espíritu en el sentido objetivo de la expresión como representación, exteriorización ${ }^{15}$. En esta teoría del lenguaje como expresión el núcleo está ocupado por el concepto, tal como puede verse en Hegel y tal como va a asumir Gadamer en su hermenéutica.

\section{La teoría hegeliana del lenguaje}

Hegel considera el lenguaje como una parte de la imaginación. Esta tiene su lugar en el espacio de la inteligencia, dentro de cuyo espacio Hegel distingue tres momentos: intuición, representación y pensamiento; a cada uno de los cuales le corresponde un producto: la imagen, el recuerdo y el concepto. Los dos primeros momentos de la inteligencia con sus dos productos correspondientes encajan dentro de lo que Hegel llama representación (Vorstellung). La representación es intuición recordada e interiorizada. En el momento de la representación la imagen se libera de la inmediatez de la intuición y pasa a adquirir independencia con respecto a las cosas de que es imagen. La imagen recordada deja de estar "ahí" y pasa a formar parte del pozo inconsciente de la inteligencia. "Comprender la inteligencia en tanto que es este pozo oscuro en el que se guarda un mundo infinito de numerosas imágenes y representaciones, sin que estén en la conciencia, es por un lado la exigencia universal de comprender el concepto como concreto, de comprenderlo como la semilla, por ejemplo, que contiene de manera positiva, como posibilidad virtual, todas las determinidades que sólo vienen a la existencia en el desarrollo del árbol... La inteligencia es como tal la existencia libre del ser-en-sí que en su desarrollo se ha recordado dentro de sí. Por otro lado,

${ }^{13}$ Ibídem, 597.

${ }^{14}$ G. DeLEUZE, Spinoza y el problema de la expresión, trad. H. Vogel, Muchnik editores, Barcelona, 1996.

15 Ibídem, 597. 
por tanto, hay que captar la inteligencia como este pozo inconsciente, es decir, como universal existente en el que lo distinto no está puesto aún como discreto. $\mathrm{Y}$ este en-sí es precisamente la primera forma de la universalidad que se ofrece en el representar" ${ }^{16}$.

A partir de este momento la inteligencia es como un depósito propio de materiales gracias al cual se independiza del mundo exterior de las cosas y puede producir sus propios productos a través de la reproducción de los recuerdos en ella conservados. El primer producto en este proceso de reproducción por parte de la inteligencia (el símbolo) es un resultado de la imaginación reproductora, que encuentra su límite en la pasividad de la impresión. En este primer producto la imaginación reproductora no puede reproducir sino aquello que conserva en ella misma. Pero ese límite de la imaginación reproductora puede ser rebasado por la actividad de la imaginación productiva, que no se limita a reproducir lo que ha intuido, sino que además puede producir signos dotados de significado. "Sin embargo, de esta demostración subjetiva contenida en el símbolo, inmediatizada por la imagen, la inteligencia pasa necesariamente a la demostración objetiva en y por sí de la representación general. Por este movimiento dialéctico, la representación general llega al punto donde ya no tiene necesidad para su demostración del contenido de la imagen, en donde se demuestra, asimismo, en y por sí, y en donde, por consiguiente, se afirma de una manera inmediata. Ahora bien, como la representación general que se ha liberado del contenido de la imagen llega a ser un ente intuitivo en una materia exterior elegida voluntariamente por ella, aporta lo que se llama signo, que se debe distinguir de una manera determinada del símbolo" ${ }^{17}$.

Con la producción de signos el trabajo de la inteligencia aboca a su exteriorización, es decir, se concreta en una expresión que se coloca fuera de la inteligencia, y que está dotada de un contenido interior. Con el signo abandonamos el espacio interior de la inteligencia y entramos en el campo exterior del lengua-

${ }^{16}$ G. F. W. HeGEL, Enciclopedia de las ciencias filosofficas, trad. R. Valls Plana, Alianza, Madrid, $1997, \& 453,494-495$.

${ }^{17}$ Ibídem, Zusatz al \& 457. Este Zusatz no está traducido en la edición castellana citada. Esta diferencia que Hegel establece entre signo y símbolo le diferencia también de Gadamer. Este conecta con la interpretación clásica del símbolo, mientras que Hegel lo hace con la interpretación moderna o romántica. Para estos temas puede consultarse: T. TODOROV, Teorias del simbolo, trad. E. Pezzoni, Monte Ávila, Caracas, 1981. 
je, que da a las intuiciones y a las representaciones una segunda existencia. «La locución (la palabra) y su sistema, el lenguaje, da a las sensaciones, intuiciones y representaciones una segunda existencia superior a su existencia inmediata; una existencia que vale en el campo del representar ${ }^{18}$.

Esta segunda existencia es lo que Hegel llama significación, que él califica como idealidad, que es la misma expresión que utiliza Gadamer para calificar el lenguaje escrito. Esa idealidad es un "querer decir» al que Hegel da el nombre de "alma", en cuanto que ésta es la actividad animadora del cuerpo inerte del significante. "Cuando la inteligencia marca un ser con un signo es que, por decirlo así, está lleno del contenido de la intuición y comunica a la materia sensible un alma, una significación que le es extrañan ${ }^{19}$. Desde el momento en el que el hombre dispone de signos, éstos relevan a la intuición y pasan a ser el contenido fundamental del espíritu. Esa sustitución de la intuición por el signo quiere decir que la intuición sensible (significante) se desvanece y en su lugar aparece la significación, la idealidad significada, el concepto entendido como significación. Con la aparición de la palabra, sonido articulado, se hacen innecesarias tanto la intuición como la imagen y es la palabra la que pasa a ser el elemento fundamental de la inteligencia. Pensamos en las palabras; y son éstas las que dan al pensamiento su existencia más alta y verdadera. El signo expresa y representa un contenido: el pensamiento mismo. Hegel compara en la Enciclopedia al signo con "la pirámide en la cual se ha colocado un alma extraña y la cobija" ${ }^{20}$. Podemos decir que para Hegel es insensato querer pensar sin palabras.

En este punto la filosofía hermenéutica de Gadamer enlaza con Hegel y con el pensamiento clásico, que consideran que el conocimiento filosófico es un hacer que requiere el trabajo del concepto. Pero la hermenéutica, como experiencia del pensamiento, va más allá de la dialéctica del concepto hegeliano, que no ve en éste más que un punto de vista. «El movimiento de la interpretación no es dialéctico tanto porque la parcialidad de cada enunciado pueda complementarse desde otro punto de vista - veremos que esto no es más que un fenómeno secundario en la interpretación-, como sobre todo porque la palabra que alcanza el

${ }^{18}$ Ibídem, \& 459, 501. Puede consultarse sobre este tema: J. SIMON, Filosofia del signo, trad. A. Agud, Gredos, Madrid, 1998.

${ }^{19}$ Ibídem, \& 457. Zusatz no traducido en la edición castellana citada.

${ }^{20}$ Ibídem, \& 458, pág. 459. 
sentido del texto en la interpretación no hace sino traer al lenguaje el conjunto de este sentido, esto es, poner en una representación finita una infinidad de sentidon" ${ }^{21}$.

\section{La dialéctica de Hegel y la hermenéutica de Gadamer ante el concepto}

La dialéctica hegeliana del pensamiento se manifiesta admirablemente en el análisis que Hegel hace de la frase especulativa en la que aparece con claridad «la sumisión del lenguaje a su enunciación", motivo por el cual no llega a alcanzar "la dimensión de la expresión lingüística del mundo» ${ }^{22}$, que es precisamente lo que caracteriza a la filosofía hermenéutica del lenguaje y lo que la diferencia de la dialéctica hegeliana del mismo. «Pues lo cierto es que el lenguaje mismo tiene algo de especulativo en un sentido completamente distinto: no sólo en el sentido hegeliano de la prefiguración instintiva de las relaciones lógicas de la reflexión, sino como realización de sentido, como acontecer del hablar, del entenderse, del comprender. Esta realización es especulativa en cuanto que las posibilidades finitas de la palabra están asignadas al sentido de su referencia como a una orientación hacia el infinito" ${ }^{23}$.

Lo especulativo del lenguaje para la hermenéutica reside en el hecho de que el que habla no copia con sus palabras lo que es, sino que expresa y da la palabra a una relación con el conjunto del ser. «El poema, como obra y creación lograda, no es ideal sino es espíritu reanimado desde la vida infinita. (También esto recuerda a Hegel). En él no se designa o significa un ente, sino que se abre un mundo de lo divino y de lo humano. La enunciación poética es especulativa porque no copia una realidad que ya es, no reproduce el aspecto de la especie en el orden de la esencia, sino que representa el nuevo aspecto de un mundo en el medio imaginario de la invención poética» ${ }^{24}$.

21 H.-G. GADAMER, Verdad y método, 557.

22 Ibídem, 460 y 461.

23 Ibídem, 561.

24 Ibídem, 563. Esta idea gadameriana de lo especulativo lleva consigo la sustitución del mentalismo como vía regia hacia el concepto por el análisis semántico de las expresiones linguiísticas, tal como puede apreciarse muy bien en la interpretación que Husserl hace de la expresión en los 16 primeros párrafos de la primera de sus Investigaciones lógicas. Véase E. HuSSERL, Investigaciones lógicas, trad. J. Gaos, R. de Occidente, Madrid, 1976, 236 y ss. 
La hermenéutica de Gadamer da primacía al oír sobre el ver. Y desde el paradigma del oír la tradición alcanza a los que viven en el presente. El lenguaje propio del acontecer hermenéutico no es tal lenguaje ni como gramática ni como léxico, sino como la voz que da la palabra a la tradición. «En esto se hace presente que la interpretación no es mera reproducción o mero referir el texto transmitido, sino que es como una nueva creación del comprendern ${ }^{25}$.

Esta consideración del lenguaje desde el punto de vista de la voz es quizá la característica más peculiar de la teoría gadameriana del lenguaje, en la cual el lenguaje no es visto como una "forma" al estilo de Humboldt, ni desde el punto de vista del "uso" tal como hace el pragmatismo, sino como una fuerza que a partir de un centro - la literalidad - pone en funcionamiento una totalidad de sentido, que subyace como virtualidad en el lenguaje literalizado. La hermenéutica gadameriana entiende el lenguaje literalizado como el lugar en el que se realiza nuestra experiencia del mundo. Por eso su concepción del lenguaje se distingue de la medieval, que veía al lenguaje como una perfección de la species, y de la moderna que lo ve como un instrumento. El lenguaje para la hermenéutica gadameriana es un acontecer "que sin poder decirlo enteramente pone en juego, sin embargo, todo un conjunto de sentido" ${ }^{26}$.

Pues bien, ese conjunto de sentido era para el mundo griego el pensamiento, al que los griegos denominaron "noûs». "La metafísica griega, que piensa el ser de lo que es, piensa este ser como un ente que se cumple o realiza a sí mismo en el pensar. Este pensar es el pensamiento del noûs, que se piensa como el ente supremo y más auténtico, el que reúne en sí el ser de todo lo que es. La articulación del logos da expresión a la estructura de los entes, y este su acceso al lenguaje no es para el pensamiento griego otra cosa que la presencia de los entes mismos, su alétheia. Por referencia a la infinitud de este presente, el pensamiento humano se piensa a sí mismo como por referencia a su posibilidad plena, a su divinidad ${ }^{27}$.

La dialéctica hegeliana enlaza en este punto con la dialéctica griega, pero se queda corta con respecto a la hermenéutica, que piensa desde el lenguaje literalizado como centro, lo que significa que "visto desde el intérprete, 'acontecer'

$\begin{array}{ll}25 & \text { Ibidem, } 566 . \\ 26 & \text { Ibidem, } 549 . \\ 27 & \text { Ibidem, } 547 .\end{array}$ 
quiere decir que no es él el que, como conocedor, busca su objeto y 'extrae' con medios metodológicos lo que realmente se quiso decir y tal y como realmente era, aunque reconociendo leves obstáculos y desviaciones condicionados por los propios prejuicioss ${ }^{28}$.

\section{El lenguaje hermenéutico como lenguaje del texto}

El lenguaje del texto es el medio en el que se realiza la conversación hermenéutica entre la tradición y el intérprete, entre el texto y el lector. Y ese lenguaje es el centro especulativo en el que convergen e interactúan el yo y el mundo. Esa convergencia e interacción es un acontecer siempre abierto al que constantemente está accediendo el sentido, lo que hace de la lectura un proceso siempre abierto. Esta interpretación de la lectura como proceso abierto permanentemente significa que Gadamer no ve el lenguaje desde el punto de vista de los nombres con su correspondiente teoría del nombrar, cuya función fundamental estaría en la designación; ni tampoco lo ve desde el punto de vista del hablar, cuya función fundamental sería el uso, sino desde el punto de vista del decir. El lenguaje dice el mundo y lo hace por medio de constelaciones objetivas de conceptos a través de las cuales el mundo accede al lenguaje, que logra su propio sentido en el mutuo entendimiento entre los interlocutores. «El entendimiento como tal no necesita instrumentos en el sentido auténtico de la palabra. Es un proceso vital en el que vive su representación una comunidad de vida. En este sentido el entendimiento humano en la conversación no se distingue del que cultivan los animales unos con otros. Sin embargo, el lenguaje humano debe pensarse como un proceso vital particular y único por el hecho de que en el entendimiento lingüístico se hace manifiesto el 'mundo'" ${ }^{29}$.

El lenguaje como decir, lo mismo que la obra de arte, tiene su paradigma en el juego como esa actividad a través de la cual la tradición sigue hablando en el presente a cualquier lector que entre en comunicación con el texto. «Lo que nos sale al encuentro en la experiencia de lo bello y en la comprensión del sentido de la tradición tiene realmente algo de la verdad del juego. En cuanto que comprendemos estamos incluidos en un acontecer de la verdad ${ }^{30}$.

\footnotetext{
28 Ibidem, 552-553.

29 Ibídem, 535.

30 Ibídem, 585.
} 
Gadamer ve el lenguaje como una realidad autónoma (escritura) dotada de fuerza propia. «La lengua es, en realidad, la palabra única cuya virtualidad nos abre la infinitud de la continuidad del discurso, y del discurso con los otros, y de la libertad de 'decirse' y de 'dejar de decirse'. No es su convencionalidad elaborada, no es el haz de pre-esquematizaciones del que estamos cargados, sino la potencia generadora y creadora de ofrecer sin cesar un tal conjunto fluidon ${ }^{31}$.

En el caso de Gadamer lo importante de la comprensión lingüística es una teoría de la lectura a través de la cual lleguemos a comprender nuestro mundo, cosa que ocurre por la mediación del lenguaje. La experiencia que tenemos de nuestro mundo se nos da a través del lenguaje. La misma experiencia del trabajo y de la dominación se nos da como una experiencia lingüística. En nuestro intento de comprensión del mundo no podemos ponernos por detrás del lenguaje como pretende Koselleck cuando, diferenciando entre Histórica y hermenéutica, escribe que «la Histórica remite - formulado en términos sencillos- a nexos de acciones, a formaciones de finitud en un ámbito también extralingüístico; la hermenéutica remite a su comprensión ${ }^{32}$.

La diferencia fundamental entre la hermenéutica gadameriana y la Histórica de Koselleck reside en el paradigma en que uno y otro se sitúan al filosofar. Gadamer filosofa desde el ser que es lenguaje y que a través de la lectura se libera y nos libera en el presente. Koselleck, en cambio, lo hace pensando en la estructura de la sociedad, que a través de su evolución va abriendo la historia hacia una mayor amplitud. «El historiador [...] se sirve básicamente de los textos sólo como testimonios para averiguar a partir de ellos una realidad existente allende los textos. Por consiguiente, tematiza, más que todos los otros exegetas de textos, un estado de cosas que en cualquier caso es extratextual, aun cuando él constituya su realidad sólo con medios lingüísticos ${ }^{33}$. Lo importante para la filosofía de Koselleck no es una teoría catártica de la lectura, sino una teoría explicativa de la realidad allende los textos. Gadamer filosofa desde la tradición de las ciencias humanas y literarias, mientras que Koselleck lo hace desde la tradición de las

${ }^{31}$ H.-G. GADAMER, Verdad y método II, 201.

32 R. KOSELLECK, y H.-G. GADAMER, Historia y hermenéutica, trad. F. Oncina, Paidós, Barcelona, $1997,87$.

${ }^{33}$ Ibídem, 91. 
ciencias de la sociedad. Y por eso piensa que «la Histórica es fácilmente discernible de una hermenéutica ligada al texto" ${ }^{34}$.

\section{Conclusión}

Vamos a concluir nuestro trabajo con una diferenciación entre las tres filosofías del concepto a las que he aludido en las páginas anteriores: Hegel, Gadamer y Koselleck. En las tres el concepto actúa como nexo de unión entre ser y pensamiento gracias a que el concepto es lenguaje. Pero esa cualidad del concepto como lenguaje tiene sus peculiaridades en cada uno de estos tres filósofos, que son las que queremos destacar en esta conclusión. Para Hegel el lenguaje es signo; y éste tiene un cuerpo (significante) y un alma (significado), siendo el concepto el alma entendida aristotélicamente como principio de vida. El significante es la tumba en la que está depositado el cuerpo muerto (significante), que tiene que ser vivificado por el alma (significado). En términos religiosos podemos decir que el concepto es el espíritu vivificador de los cuerpos muertos.

Para Gadamer, en cambio, el lenguaje es símbolo, que es en sí mismo vida. La palabra, que es símbolo, es vida en sí misma, que fluye como sentido en el concepto, el cual se distingue de la palabra. La vida del concepto es ideal, eterna y se hace manifiesta en cada presente gracias a la voz que le presta el intérprete. Pero Gadamer, como hemos visto, caracteriza el concepto como el espacio en el que emana el sentido que viene de la tradición. El concepto es un espacio (tópos), que posibilita que acceda o emane el sentido, que nos permite comprender e interpretar la realidad sin necesidad de salir del lenguaje. Así pues, para Gadamer la grandeza del símbolo está en su plenitud, así como la del concepto está en su disposición para el sentido.

Koselleck se sirve también de la metáfora de la tumba, pero la interpreta en un sentido muy diferente a Hegel. En el uso de esta metáfora Koselleck se apoya en un texto de Fichte que interpreta la realidad como la tumba del concepto ${ }^{35}$. Es

34 Ibidem, 93.

35 J. G. FICHTE, "Exposición de la doctrina de la ciencia» (1804), en Doctrina de la ciencia, trad. J. Cruz, Aguilar, Madrid, 1973, 220. "La vida reside en la luz, que sólo es una cosa con la realidad, y la realidad se absorbe en ella; y toda esta realidad como tal, en su forma, no es más que la tumba del concepto que quiso aventurarse a la luz». Este texto es citado por Koselleck al final de Historia y Hermenéutica, para diferenciar esas dos tradiciones. 
decir, que tanto Hegel como Gadamer no salen del ámbito del lenguaje, que es el ámbito en el que se conserva la realidad, ya sea objetivamente como piensa Hegel, ya sea como experiencia como piensa Gadamer. Koselleck, en cambio, sale del ámbito del lenguaje a la realidad y considera que es ésta la que vivifica al lenguaje y lo llena de contenido. La realidad va desarrollándose a lo largo del tiempo y en ese desarrollo se va enriqueciendo con nuevos contenidos que quedan registrados en el lenguaje. Los nuevos acontecimientos que van ocurriendo van llenando de nuevos significados a los conceptos, que se van enriqueciendo gracias a la evolución de la realidad. El lenguaje conceptual para Koselleck es un sistema de registros, un concentrado de muchos contenidos en el que la realidad deja sus huellas, que el historiador tiene que interpretar para la elaboración de sus historias. Los conceptos son un sistema de registros, un concentrado de muchos contenidos que posibilita la escritura de las historias por parte de los historiadores.

La diferencia fundamental entre la dialéctica de Hegel, la hermenéutica de Gadamer y la Histórica de Koselleck reside precisamente en el modo como cada una de estas filosofías interpreta el concepto: como alma vivificadora, Hegel; como sentido que fluye, Gadamer; y como registro de los procesos por los que ha discurrido la realidad, Koselleck. Este entiende el concepto como polisémico, característica que podemos explicar diciendo que es como un sistema de significados estructurados en torno a un núcleo, que funciona como el punto de atracción y organización de la constelación de significados que es el concepto. Un concepto nunca puede ser unívoco, dado que es el resultado de la totalidad de un contexto de experiencia. Por eso Koselleck gusta de citar ese texto de Nietzsche en el que este filósofo dice que sólo es definible aquello que no tiene histo$\mathrm{ria}^{36}$, cosa que no ocurre con ningún concepto, que para Koselleck es ese espacio privilegiado en el cual se hace presente la historia; hasta el punto de que sólo la historia de los conceptos posibilita las historias como narración. De manera que podemos decir que las historias narrativas no son otra cosa que la explicitación de la historia conceptual, que es la que hace posibles a aquellas. Los conceptos son como la sustancia del tiempo histórico. Esto es lo que hace que para Koselleck la «filosofía de la historia» tal como se constituyó en la Ilustración sea un elemento fundamental de la historia. «La Historia como tal no llegó a ser una ciencia propiamente dicha hasta que no adquirió [...] un nuevo campo de expe-

${ }^{36}$ F. NieTzSCHE, La genealogia de la moral, trad. A. Sánchez Pascual, Alianza, Madrid, 1974, 91. 
riencia. [...] La formación de la filosoffa de la historia es el inicio de este proceso" ${ }^{37}$. Así pues, para Koselleck la historia siempre ha sido una "ciencia de experiencia", lo que ocurre es que el concepto de experiencia tiene usos diferentes según se trate de un momento u otro del tiempo. "Hacer una experiencia' quiere decir ir de aquí hacia allá para experimentar algo; se trata al mismo tiempo de un viaje de descubrimiento. Pero únicamente a partir del informe sobre ese viaje y de la reflexión del informe surge la historia como ciencia. Cuando hablemos en adelante de estratos del tiempo, deberá pensarse también en los hallazgos de la experiencia, descifrados analíticamente en tres estratos" ${ }^{38}$. Esos tres estratos del tiempo son: el de los acontecimientos, el de las estructuras y el de los conceptos como "depósitos de experiencias». En el tercero de los casos abandonamos el plano de la biología con sus límites en el ámbito de individuos y generaciones y entramos en el plano de la cultura, que nos permite un tipo de generalidad que no permite la vida ni de los individuos, ni de las generaciones. Por eso escribe Koselleck que «los conceptos sociales y políticos contienen una concreta pretensión de generalidad y son siempre polisémicos $-\mathrm{y}$ contienen ambas cosas no sólo como simples palabras para la ciencia de la historia" ${ }^{39}$.

Podemos decir que tanto en el caso de Gadamer como en el de Koselleck se habla de una "historia de los efectos"; pero con una importante diferencia: que en el caso de Gadamer la historia de los efectos tiene que ver con la interpretación de los textos; mientras que en el de Koselleck tiene que ver con los hechos de la realidad. Son los acontecimientos y su eficiencia los que posibilitan que los conceptos adquieran nuevos significados.

En definitiva y para concluir podemos decir que la diferencia fundamental entre Gadamer y Koselleck en relación con el concepto consiste en que Koselleck lo considera desde el punto de vista de la ciencia y su lógica, mientras que Gadamer, siguiendo a Aristóteles, lo hace desde el punto de vista de las lenguas naturales y su lógica. Y por eso escribe que «la articulación de palabras y cosas, que emprende cada lengua a su manera, representa en todas partes una primera conceptualización natural muy lejana al sistema de la conceptualización cientí-

37 R. KoselleCK, historia/Historia, trad. A. Gómez, Trotta, Madrid, 2004, 47.

${ }^{38}$ R. KOSELLECK, Los estratos del tiempo: estudios sobre la historia, trad. D. Innerarity, Paidós, Barcelona, 2001, 36.

39 R. KoselieCK, Futuro pasado, trad. N. Smilg, Paidós, Barcelona, 1993, 116. 
fica. Se guía por entero según el aspecto humano de las cosas, según el sistema de sus necesidades e intereses. Lo que para una comunidad lingüística es esencial para cierta cosa, puede reunir a ésta con otras cosas por lo demás completamente distintas bajo la unidad de una denominación, con sólo que todas ellas posean este mismo aspecto esencial. La denominación (imposición de nombre) no responde en modo alguno a los conceptos esenciales de la ciencia y a su sistema clasificatorio de géneros y especies. Al contrario, vistos desde aquí muchas veces son meros accidentes los que guían la derivación del significado general de una palabra ${ }^{40}$. La diferencia está, pues, en que Gadamer es hermeneuta y Koselleck estructuralista; y como consecuencia de ello el referente último de uno y otro es diferente; en el caso de Koselleck es la ciencia con su remisión a la realidad, y en el caso de Gadamer es el hombre, cuya pregunta última es siempre por el sentido, que queda condensado y acumulado en el texto. De ahí que en la respuesta de Gadamer a Koselleck, aquel concluya su respuesta con estas palabras: "Nunca deberíamos renunciar a insertar las duras realidades de la historia, siempre y de nuevo, en nuestras posibilidades humanas" ${ }^{41}$. Así pues, en uno y otro la historia está detrás de los conceptos y por eso admitirían lo que Nietzsche dice del concepto: que es "una síntesis de sentidos". La diferencia reside en la explicación que cada uno de ellos da de la síntesis. Gadamer considera que es el lenguaje humano (texto) el que está detrás de esa síntesis; mientras que para Koselleck quien está detrás de esa síntesis es la realidad misma con sus acontecimientos, que son los que van llenando de sentido los conceptos al aportar "nuevas experienciasm. Es decir, que para Koselleck la experiencia tiene como suelo fundamental del que procede a la realidad tal como la misma se ha ido desarrollando; mientras que para Gadamer la experiencia es la experiencia hermenéutica, que procede del lenguaje mismo como condensador de la realidad, tal y como el mismo ha cristalizado en lo que la hermenéutica llama texto.

40 H.-G. GaDAmer, Verdad y Método I, 522.

${ }^{41}$ R. KOSELleck y H.-G. GadAmer, Historia y hermentutica, 106. 